\title{
EVALUATION OF BIOACTIVITY OF JAGGERY PREPARED USING PLANT MUCILAGE AS CLARIFICANT
}

\author{
HARISH NAYAKA MA ${ }^{1}$, LAVA CHIKKAPPAIAH ${ }^{1}$, VENKATESH KS ${ }^{1}$, GUNASHREE BS ${ }^{2}$, SUDHARSHAN ${ }^{1}$
}

${ }^{1}$ Department of Studies in Sugar Technology, Sir. M. Visvesvaraya Postgraduate Centre, University of Mysore, Tubinakere, Mandya, Karnataka, India. ${ }^{2}$ Department of Studies and Research in Microbiology, Mangalore University Postgraduate Centre, Chikka Aluvara, Kodagu, Karnataka, India. Email: harish_nayaka4@yahoo.com

Received: 25 September 2017, Revised and Accepted: 12 July 2018

ABSTRACT

Objective: The aim of the study was to prepare the jaggery using plant mucilage as clarificants and to evaluate the bioactivity of jaggery by determining total phenols, total flavonoids, reducing power, antibacterial activity and antihelmintic activity.

Methods: Jaggery was prepared from sugarcane variety Co-80632 using five plant mucilage as clarificants, namely Aloe vera, flax seeds, fenugreek, purslane, and malabar spinach at three different concentrations, i.e., $0.1 \%, 0.2 \%$ and $0.4 \%$ of raw sugarcane juice. The characteristic bioactivities such as total phenol content by Folin-Ciocalteu method, flavonoids content by spectrophotometer method, reducing power assay by measuring the absorbance at $700 \mathrm{~nm}$, antibacterial activity by well-diffusion method and antihelmintic activity by in vitro were determined.

Results: The highest total phenolic content was observed in jaggery prepared using plant mucilage clarificant of $A$. vera (JAV4 [3.68 \pm 0.02 ]) and Fenugreek seeds (JFG4 [3.61 \pm 0.02$]$ ) at $0.4 \%$ followed by them at $0.2 \%$ and $0.1 \%$ concentration, respectively. Similarly, a significant amount of total flavonoids content was elevated only in $0.4 \%$ plant mucilage clarificants of Aloe vera-treated experimental group jaggery (0.73 \pm 0.01 ) compared to control $(0.61 \pm 0.02)$. Further, the antioxidant activity of jaggery was evaluated by reducing power. The increased absorbance at 700 nm indicated the presence of reducing power. At $10 \mathrm{mg} / \mathrm{ml}$ concentration, an absorbance unit of 1.93 and 1.80 was observed for jaggery prepared using $0.4 \%$ concentration of $A$. vera and fenugreek seed mucilage clarificants. Antihelmintic activity of jaggery showed dosage depended on the pattern where with the increase in the concentration of mucilage, the antihelmintic activity enhanced. $A$. vera mucilage showed maximum antihelmintic activity at $0.4 \%$ concentration with paralytic time (28.6 $\mathrm{min})$ and death time (39.6 $\mathrm{min})$.

Conclusion: Jaggery prepared using plants mucilaginous clarificants is the richest source of polyphenols such as phenolic acids and flavonoids, thereby contributed to the enhancement of bioactivity such as antioxidant, antibacterial and antihelmintic activity. Thus, jaggery prepared using plant mucilage as clarificants is a novel nutraceutical product which can supplement the nutrients along with various medicinal properties through antioxidant, antibacterial and antihelmintic activity.

Keywords: Jaggery, Plant mucilage, Clarificants, Total phenols, Antihelmintic activity.

(C) 2018 The Authors. Published by Innovare Academic Sciences Pvt Ltd. This is an open access article under the CC BY license (http://creativecommons. org/licenses/by/4. 0/) DOI: http://dx.doi.org/10.22159/ajpcr.2018.v11i11.22764

\section{INTRODUCTION}

From times immemorial food habits of human beings included natural sweeteners and their importance recognized in Indian diets as well. Jaggery, the well-known sweetening agent, prepared by concentration of sugarcane juice is added to beverages and foods for increasing palatability. The practice of feeding jaggery to mothers and cows during the lactation period just after delivery is common in India [1]. Jaggery was reported to contain sucrose (65-85\%), reducing sugar $(10-15 \%)$, proteins $(4 \%)$, minerals $(1 \%)$ and vitamins and phenolic compound (280-320 mg/100 g) [2]. Jaggery being a least processed sugar retains much of the phytochemicals that are present in sugarcane juice and exhibits various health benefits [3]. Indian Ayurveda medicine considers jaggery as a medicinal sugar and jaggery has been reported to possess protective effect against smoke-induced lung damage, arsenicinduced chromosomal aberrations, arteriosclerosis and cytoprotection against oxidative damage [4-7].

Sugarcane contains various phenolic compounds, and its extracts have displayed a wide range of biological activities including antioxidant, anti-inflammatory, antithrombosis, immune stimulation and anti-stress effects [8-11]. It is also reported that natural sweeteners such as honey, palm-jaggery, and cane jaggery to possess antihelmintic activity [12]. A study on antioxidant properties of fortified jaggery with Neem leaf has exhibited antioxidant activity [13]. The jaggery enriched with ginger in different sugarcane varieties was reported to have elevated its antioxidants properties [14].

The interest in plant phenolics has considerably increased in recent years because of their possible role in the prevention of oxidative stress-induced diseases such as cardiovascular complications, diabetes, ulcers and cancer [15-18]. The search of antioxidants in jaggery is part of the extended interest in antioxidant phenolics driven by the quest of exploiting their putative health effect through food [19]. The bioactivity of these natural sugars can be anticipated, as they contain phytochemicals to a different extent depending on their manufacturing process.

The indiscriminate level of addition of chemical clarificants such as Hydrous, sodium carbonate, sodium bicarbonate, superphosphate and alum during jaggery production has led to downfall of jaggery market due to its poor keeping quality of jaggery during storage $[20,21]$. Due to health consciousness BIS has set up guidelines for the chemical clarificants and should be used within a safe limit. To overcome the effect of chemical clarificants residues in the jaggery, vegetable clarificants can be used as potential alternatives to replace chemical clarificants/ synthetic clarificants. The wide uses of mucilaginous plants sources such as Hibiscus ficulneus (Deola), Hibiscus esculentus (Bhindi), Cadia celcina (Sukalai), Bombax malabaricum (Semal bark), Grewia asiatica (Falsa), Arachis hypogea (Ground nut), Recinus communis (Castor seed), 
Manihot esculentum (Tapioca) and Glycine max (Soybean) are reported in clarification of jaggery [20-23]. The mucilage from plant sources was already exploited in the pharmaceutical, cosmetic field and their therapeutical application [24].

In the present study, the mucilage extracted from A. vera, flax seeds, fenugreek seeds, purslane and malabar spinach was used as clarificants at three different concentrations, i.e., $0.1 \%, 0.2 \%$, and $0.4 \%$ of raw sugarcane juice. The biological activity of jaggery prepared using plant mucilage clarificant was determined by evaluating total phenol content, total flavonoids content, reducing power, antibacterial activity and antihelmintic activity

\section{METHODS}

\section{Samples}

The sugarcane variety Co-86032 of 10 months age was collected from Zonal Agricultural Research Station, V.C. Farm, Mandya, Karnataka. The plant's materials such as Malabar Spinach, Purslane, and A. vera were collected from field and flax seeds and fenugreek seeds were purchased from Shop, Mysore. The plant materials were taxonomically identified and authenticated at Regional Ayurveda Research Institute for Metabolic Disorder, Bengaluru, India.

\section{Extraction of mucilage}

The extraction of mucilage from the plant sources was carried out as per method [25]. The mucilage from A. vera was extracted from the leaf by peeling and kept overnight at below $20^{\circ} \mathrm{C}$. The slurry/mucilage is obtained by filtering the extract through muslin cloth [26]. Flax seeds and fenugreek seeds were crushed and soaked in 1:5 W/V of water for $6 \mathrm{~h}$ and boiled in water bath for $5 \mathrm{~h}$ then cooled at below $20^{\circ} \mathrm{C}$ overnight. The extract was filtered through a muslin cloth to obtain mucilage/ slurry [27]. Cleaned leaves and stem of purslane and Malabar spinach plant was chopped into small pieces and soaked in $1: 3 \mathrm{~W} / \mathrm{V}$ of water for $6 \mathrm{~h}$ and boiled in water bath for $5 \mathrm{~h}$ then cooled below $20^{\circ} \mathrm{C}$ overnight. The extract was filtered through a muslin cloth to obtain the mucilage/ slurry $[28,29]$. The mucilage was subjected to chemical tests such as Molisch test and Ruthenium red test to confirm its identity [30].

\section{Preparation of jaggery using mucilaginous clarificants}

Five jaggery samples were prepared using $A$. vera mucilage, flax seeds mucilage, fenugreek mucilage, Purslane mucilage and Malabar spinach mucilage as clarificants at a dosage concentration of $0.1 \%, 0.2 \%$ and $0.4 \%$ (Table 1 ). The sugarcane was cleaned and washed to remove dirt and foreign particles from the surface. A two roller power crusher was used to extract the juice and the extracted juice was allowed to settle in a container where lighter fraction comprising of wax, carbon and undesirable solid particles will settle at the bottom. The semi-clear juice (supernatant) was boiled with the addition of lime (calcium hydroxide) to adjust the $\mathrm{pH}$ to neutral [31], at this stage mucilage clarificant was added in 2 to 3 sequence and scum formed during boiling was removed time to time. The boiling is continued until the juice attains a temperature of $118-120^{\circ} \mathrm{C}$ [32]. The hot syrup was allowed to cool and transferred into molds of different shapes and sizes for solidification. The solid jaggery prepared is stored under dry conditions for further analysis. Similarly, the jaggery was prepared without addition of any clarificant was used as a control for comparing purpose.

\section{Determination of total phenol content}

Total phenol content of jaggery was determined using Folin-Ciocalteu method [33]. One gram of jaggery sample was extracted with $10 \mathrm{~mL}$ of methanol:water $(50: 50, \mathrm{v} / \mathrm{v})$ solution. Then, $1 \mathrm{~mL}$ of diluted $(0.1 \mathrm{~mL}$ sample aliquot and $0.9 \mathrm{~mL}$ of distilled water) extract was mixed with $5 \mathrm{~mL}$ of Folin-Ciocalteu reagent (1:10 diluted with distilled water) and $4 \mathrm{~mL}$ of aqueous sodium bicarbonate (1 M). The solution was allowed to stand for $15 \mathrm{~min}$ and then the absorbance of the solution was measured against a blank at $765 \mathrm{~nm}$ in a spectrophotometer. A gallic acid standard curve was prepared using $0,20,40,60,80$ and $100 \mu \mathrm{g} /$ $\mathrm{mL}$ of methanol:water (50:50, v/v). Total phenol values were expressed in terms of the standard reference compound as gallic acid equivalent in milligrams per gram of jaggery.

\section{Determination of total flavonoid content}

Spectrophotometric method using aluminum chloride was used for the determination of flavonoids in jaggery with slight modification [31]. 50 microliter of jaggery sample $(10 \%)$ was added to $400 \mu \mathrm{L}$ of methanol. Then, $0.1 \mathrm{~mL}$ of $10 \%$ aluminum chloride, $0.1 \mathrm{~mL}$ of $1 \mathrm{M}$ potassium acetate and $1.8 \mathrm{~mL}$ of distilled water were sequentially added to the reaction tubes. The reaction mixture was kept at room temperature for $30 \mathrm{~min}$ and later the absorbance of the reaction mixture was measured at $415 \mathrm{~nm}$ wavelength in a spectrophotometer. A calibration curve was prepared using standard quercetin at different concentrations $(20-100 \mu \mathrm{g} / \mathrm{mL}$ in methanol). Total flavonoid content was expressed in terms of the standard reference compound as quercetin equivalent in $\mathrm{mg} / \mathrm{g}$ of jaggery.

\section{Reducing power assay}

The reducing power of jaggery samples was determined according to the method reported earlier [34]. The jaggery sample $(1-10 \mathrm{mg} / \mathrm{mL})$ was mixed with an equal volume of $0.2 \mathrm{M}$ phosphate buffer, $\mathrm{pH} 6.6$ and $1 \%$ potassium ferricyanide. The mixture was incubated at $50^{\circ} \mathrm{C}$ for $20 \mathrm{~min}$. Then an equal volume of $10 \%$ trichloroacetic acid was added to the mixture and then centrifuged at $3000 \mathrm{rpm}$ for $10 \mathrm{~min}$. The upper layer of solution was mixed with distilled water and $0.1 \%$ ferric chloride at a ratio of $1: 1: 2(\mathrm{v} / \mathrm{v} / \mathrm{v})$ and the absorbance of the solution measured at $700 \mathrm{~nm}$. The increased absorbance of the reaction mixture indicated increased reducing power.

Table 1: Preparation of mucilage clarificants for 10L Sugarcane raw Juice

\begin{tabular}{llll}
\hline Experiment & Sample code & Mucilage concentration (\%) & Quantity (g) of mucilage per 10 L of juice \\
\hline Control & JNC & No mucilage & - \\
A. vera mucilage & JAV1 & 0.1 & 10 \\
& JAV2 & 0.2 & 20 \\
Flax seed mucilage & JAV4 & 0.4 & 40 \\
& JFS1 & 0.1 & 10 \\
Fenugreek mucilage & JFS2 & 0.2 & 20 \\
& JFS4 & 0.4 & 40 \\
JFG1 & 0.1 & 10 \\
& JFG2 & 0.2 & 20 \\
Marslane mucilage & JJFG4 & 0.4 & 40 \\
& JJPS1 & 0.1 & 10 \\
& JJPS2 & 0.2 & 20 \\
& JPS4 & 0.4 & 40 \\
& JMS1 & 0.1 & 10 \\
\hline
\end{tabular}

A. vera: Aloe vera 


\section{Antibacterial property}

Antibacterial activity was determined by agar well diffusion assay [35]. For the study Gram-positive bacteria (Bacillus subtilis) and Gramnegative bacteria (Escherichia coli) were selected. Test cultures were grown on Luria Bertani Agar slants and culture densities were prepared using sterile phosphate buffer saline pH 7.2. Culture density was adjusted to $0.12-0.14$ absorbance at $530 \mathrm{~nm}$. Each test culture $(0.4 \mathrm{~mL})$ was mixed with molten cooled sterile Mueller-Hinton agar butt $(20 \mathrm{~mL})$ and was poured into $9 \mathrm{~cm}$ Petri plates. Wells of diameter $8 \mathrm{~mm}$ were bored in the agar plates. $50 \mu \mathrm{L}$ of Jaggery sample prepared in sterile distilled water was added to each well. The plates were incubated for $24 \mathrm{~h}$ at $37^{\circ} \mathrm{C}$. Results were interpreted by measuring the size of the zone diameter of inhibition surrounding the wells on the agar plates.

\section{Antihelmintic activity}

The antihelmintic activity of jaggery prepared using plant mucilage clarificants was determined according to the method described with slight modification [12]. The assay was performed in vitro using adult earthworm (Pheretima posthuma) due to their anatomical and physiological resemblance with the intestinal roundworm parasites of human beings. Briefly, $10 \mathrm{~g}$ of jaggery dissolved in $20 \mathrm{~mL}$ of distilled water was taken in $9 \mathrm{~cm}$ Petri dish and six earthworms of approximately equal size were placed in it. Piperazine hexahydrate $(10 \mathrm{mg} / \mathrm{mL})$ was used as the reference standard and distilled water as a control. All the test solutions and standard drug solution were prepared freshly before starting the experiments. The time taken for paralysis when no movement was observed even when the worms were shaken vigorously was reported. Similarly, time for the death of worms was recorded after ascertaining that worms neither moved when shaken vigorously nor when dipped in warm water. All the results were expressed as mean $\pm \operatorname{SD}(n=6)$.

\section{Statistical analysis}

All the experiments were carried out in triplicates, and the results were expressed as the mean \pm standard deviation $(n=3)$.

\section{RESULTS AND DISCUSSION}

\section{Antioxidant activity of jaggery prepared using plant mucilage clarificants}

Results of total phenolic and flavonoids content in jaggery samples prepared using plant mucilage clarificants are shown in Figs. 1 and 2 , respectively. The total phenolic content in test jaggery samples was higher than the control jaggery. A good positive correlation was observed between the concentration of plant mucilage clarificants and total phenol content. Among the test jaggery samples, jaggery prepared using $A$. vera at $0.4 \%$ concentration indicated highest phenolics content $(3.68 \pm 0.02)$ while the Malabar spinach treated jaggery had the least phenolics content $(3.51 \pm 0.01)$.

The flavonoid content of tested jaggery samples was higher than control jaggery at 0.2 and $0.4 \%$ mucilage concentrations. A. vera-treated jaggery indicated marginally higher flavonoid content compared to other plant mucilage treated jaggery samples. However, among the test jaggery samples except $A$. vera-treated jaggery, no significant differences in flavonoid content were evident.

The presence of higher total phenolic and flavonoid content in plant mucilage clarificants treated jaggery compared to control may be due to minimal chemical processing in the preparation of jaggery and maximal removal of scum, reduced preparation time followed by good jaggery yield which could have played a major role in retaining good amount of polyphenols.

Further, the antioxidant activity of jaggery prepared using plant mucilage clarificants was evaluated for reducing power. Reducing power assay provides a measure of compounds ability to donate electrons and reduce the oxidized intermediates formed in the peroxidation process. The assay was based on the reduction of the $\mathrm{Fe}^{3+}$ ferricyanide complex which was monitored by measuring the formation of Perl's blue at
$700 \mathrm{~nm}$. The increased absorbance at $700 \mathrm{~nm}$ indicated the presence of reducing power [36]. In Fig. 3 A-C, the jaggery samples exhibited in vitro ferric reducing potential in a dose-dependent manner. The absorbance of test jaggery samples increased at $700 \mathrm{~nm}$ compared to jaggery control. The reducing powers of jaggery samples at $0.1,0.2$, and $0.4 \%$ mucilage clarificants were in the order, JAV $>J F G>J F S>J P S>J M S$ $>$ JNC. At $10 \mathrm{mg} / \mathrm{mL}$ concentration, an absorbance unit of 1.93 and 1.80 was observed for jaggery prepared using $0.4 \% \mathrm{~A}$. vera and fenugreek seed mucilage (Fig. 3c). Since the test jaggery samples exhibited higher reducing power compared to jaggery without clarificants, it is certain that the increased reducing power may be attributed to the addition of plant mucilage extract for clarification which may contain antioxidant phytochemicals. The reducing power serves as a significant indicator of antioxidant activity $[13,37]$. The biomolecule, especially polyphenolic compounds, has been credited for the health-promoting properties such as prevention of chronic cardiovascular diseases [38]. The reducing power of phenolic compounds in sugarcane juice as well as in brown sugar has been reported $[39,40]$. The Millard reaction products may also contribute to the observed reducing power but to a lesser extent [41].

Jaggery shows antioxidant properties probably due to the presence of phenolic acids, flavonoids, and other phenolic compounds [9,42-45]. The health effects of antioxidants in particularly of polyphenols have still not been scientifically established as the European Food Standards Agency [46]. Jaggery being a least processed sugar retains phenolics and other phytochemicals with potent biological activities such as antioxidant, cytoprotective and antihelmintic activity as reported in the literature $[7,12,19]$.

Sugarcane juice extract contains a wide range of phenolic compounds such as flavonoids [42] and phenolic acids [41] such as apigenin, luteolin, tricin, caffeic, cinnamic acid, sinapic acids and chlorogenic acid. Jaggery showed relatively significant antioxidant activity equivalent

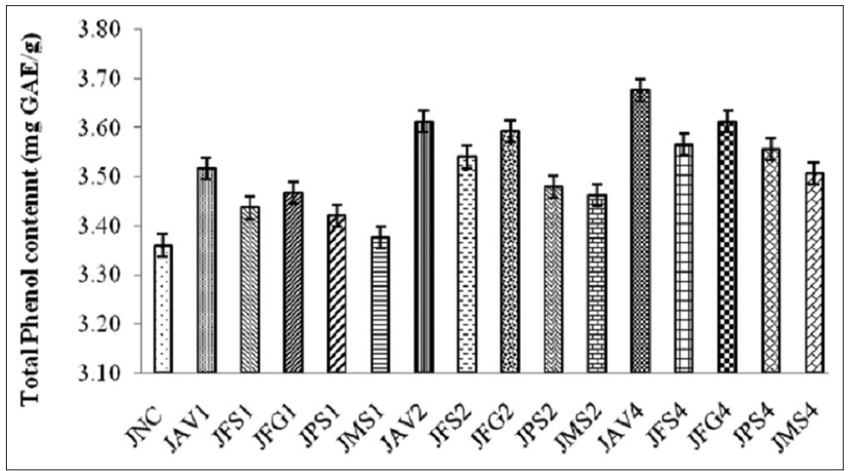

Fig. 1: Total phenolic content in jaggery prepared using plant mucilage clarificants

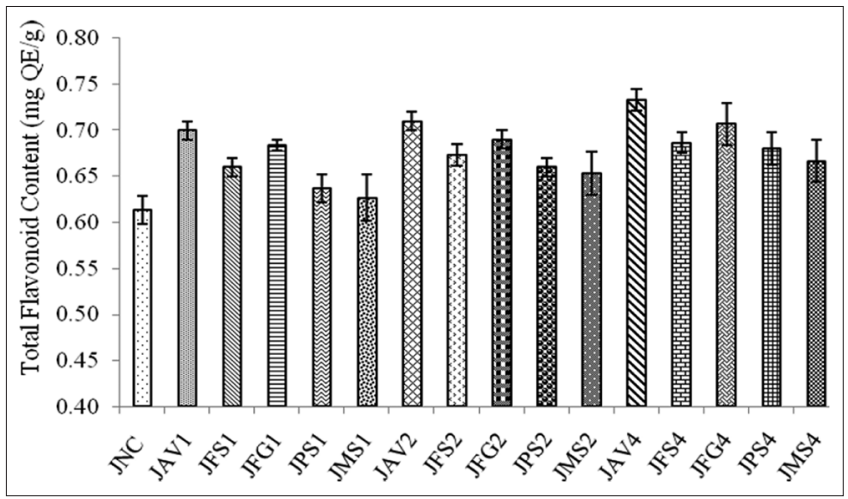

Fig. 2: Total Flavonoid contents in jaggery prepared using plant mucilage clarificants 


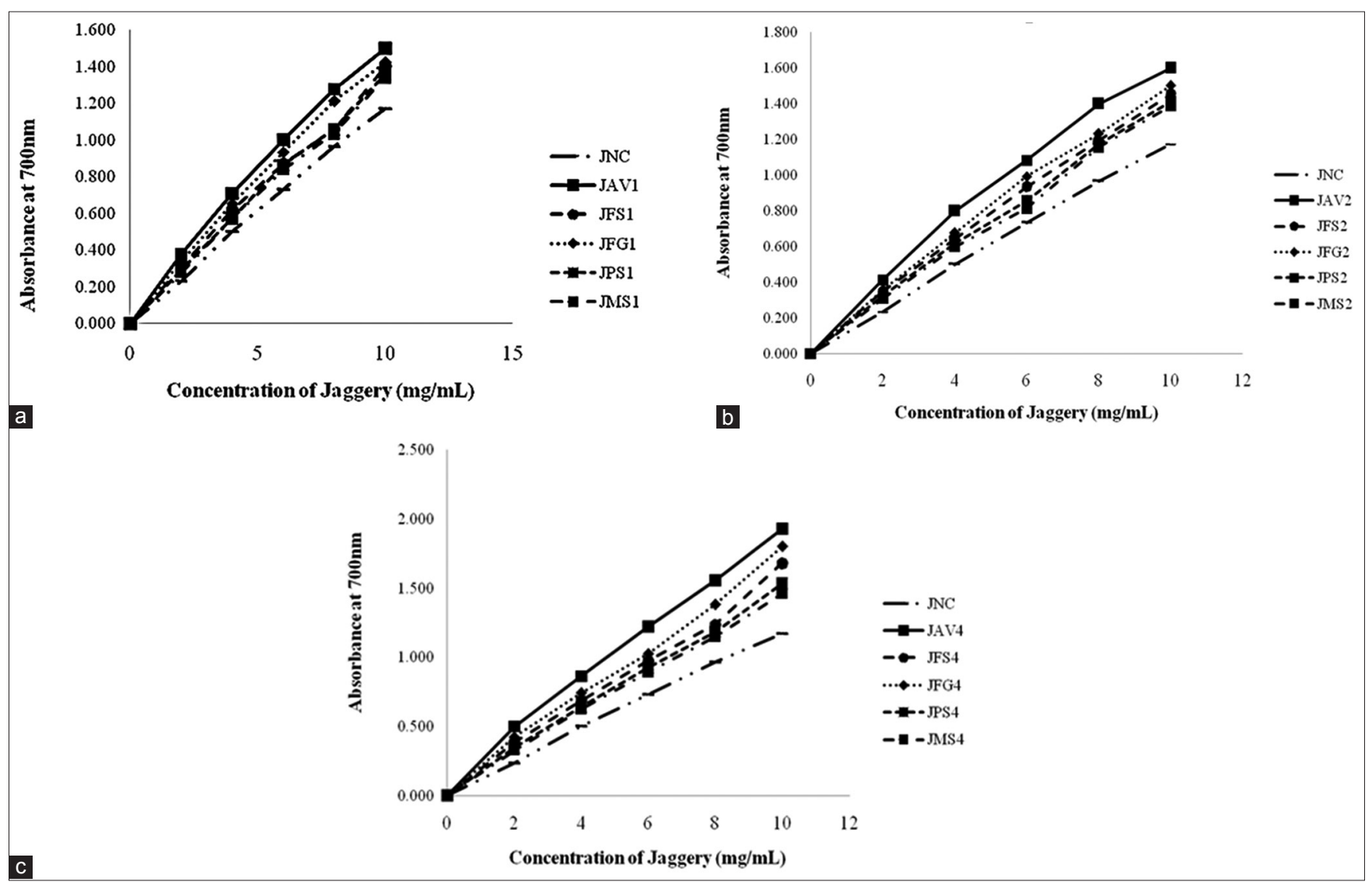

Fig. 3: (a) Reducing power of jaggery prepared using plant mucilage clarificants at $0.1 \%$ concentration, (b) reducing power of jaggery prepared using plant mucilage clarificants at $0.2 \%$ concentration, (c) reducing power of jaggery prepared using plant mucilage clarificants at $0.4 \%$ concentration

to BHT in earlier reports [47]. The traditional practice of adding antioxidants during processing can still play a very important role as added compounds have additional potential for enhancing endogenous antioxidant systems. In the present investigation, jaggery processing using plant mucilage as a clarificants led to the synergistic addition of both total phenolic and flavonoids content resulting in the increased antioxidative potential of jaggery. Free radicals are implicated in the etiology of many human diseases and antioxidant could act as potential therapeutic agents [48]. Hence, the combination of nutritional and medicinal benefits of jaggery prepared using plant mucilage as clarificants can be a potential nutraceutical food.

\section{Antibacterial activity of jaggery prepared using plant mucilage as} clarificant

The antibacterial activity of jaggery prepared using plant mucilage as clarificant along with control was determined by measuring the diameter of inhibition zone, and the results are indicated in Table 2. Among the test jaggery samples prepared using plant mucilage as clarificant, only A. vera $(34.0 \pm 2 \mathrm{~mm})$ and fenugreek $(32.0 \pm 1.00 \mathrm{~mm})$ at $0.4 \%$ mucilage concentration were effective in inhibiting the growth of Gram-positive bacteria compared to control (Table 2). Against Gramnegative bacteria $A$. vera $(25.7 \pm 0.58 \mathrm{~mm})$, fenugreek $(24.3 \pm 0.58 \mathrm{~mm})$ and flax seeds $(24.3 \pm 0.58 \mathrm{~mm})$ treated jaggery significantly inhibited growth compared to other two mucilage clarificants and control. Based on the diameter of the inhibition zone, it was observed that Gram-positive bacteria were more sensitivity to the experimental jaggery samples than Gram-negative bacteria. The antibacterial activity may be attributed to the polyphenols and antioxidant properties of the jaggery [49]. The present study showed that antibacterial activity is closely related to the concentration of phenolic and flavonoids and thus to the antioxidant capacity of the jaggery prepared using plant mucilage clarificants.
Antihelmintic activity of jaggery prepared using plant mucilage clarificants

Helmintiasis is recognized as a major problem in livestock production throughout the tropics and also for human health. The parasitic gastroenteritis infection caused by several species of intestinal helminths results in weakness, loss of appetite, decreased feed efficiency, reduced weight gain and decreased productivity [50]. Chemotherapeutics has remained as the cornerstone for the treatment of helmintic infection due to development of problems such as resistance to drug, chemical residues and toxicity, cost expensive, nonavailability, and non-adaptability of drugs in remote areas [51,52].

In vitro antihelmintic activity of jaggery derived from plant mucilage clarificants indicated significant decrease in paralytic and death time of helminths. Control jaggery (paralytic time $36.6 \pm 1.14$ and death time $47.6 \pm 0.548$ ) and $A$. vera (JAV4) plant mucilage clarificants at $0.4 \%$ treated jaggery (paralytic time $28.6 \pm 1.14$ and death time $39.6 \pm 1.14$ ) exhibited anthelmintic activity at $0.5 \mathrm{~g} / \mathrm{mL}$ concentration and the death time of worm was found to be $47.6 \mathrm{~min}$ in control versus $39.6 \mathrm{~min}$ in test jaggery as tabulated in Table 3 . Standard drug piperazine hexahydrate killed earthworm in $28.4 \mathrm{~min}$ at $10 \mathrm{mg} / \mathrm{mL}$ concentration. However, distilled water (negative control) did not show any effect on helminths.

The predominant effect of piperazine hexahydrate on the worm caused a flaccid paralysis resulting in the expulsion of the worm by peristalsis. Piperazine hexahydrate by increasing chloride ion conductance of worm muscle membrane produces hyperpolarization and reduced excitability leading to muscle relaxation and flaccid paralysis. There are reports to indicate antihelmintic activity of cane jaggery [12]. Similar results were observed in our study at $0.4 \%$ concentration of plant mucilage clarificants of $A$. vera (JAV4) treated jaggery samples. 
Table 2: Antibacterial activity of Jaggery prepared using plant mucilage clarificants

\begin{tabular}{lll}
\hline Sample & $\begin{array}{l}\text { Diameter of inhibition zone }(\mathbf{m m})^{*} \text { against Gram-positive } \\
(\boldsymbol{B} \text {. } \text { subtilis })\end{array}$ & $\begin{array}{l}\text { Diameter of inhibition zone (mm)* against Gram-negative } \\
\text { (E. coli) }\end{array}$ \\
\hline JNC & $27.0 \pm 1.00$ & $21.0 \pm 1.00$ \\
JAV1 & $30.3 \pm 0.58$ & $22.0 \pm 1.00$ \\
JFS1 & $29.3 \pm 0.58$ & $21.0 \pm 1.00$ \\
JFG1 & $30.3 \pm 0.58$ & $22.3 \pm 1.15$ \\
JPS1 & $29.0 \pm 1.00$ & $21.0 \pm 1.00$ \\
JMS1 & $28.3 \pm 0.58$ & $20.7 \pm 1.15$ \\
JAV2 & $30.3 \pm 1.53$ & $23.0 \pm 1.00$ \\
JFS2 & $30.3 \pm 0.58$ & $22.3 \pm 1.15$ \\
JFG2 & $30.0 \pm 1.00$ & $23.7 \pm 0.58$ \\
JPS2 & $29.0 \pm 1.00$ & $22.7 \pm 1.53$ \\
JMS2 & $28.3 \pm 1.53$ & $23.3 \pm 0.58$ \\
JAV4 & $34.0 \pm 2.00$ & $25.7 \pm 0.58$ \\
JFS4 & $29.7 \pm 0.58$ & $24.3 \pm 0.58$ \\
JFG4 & $32.0 \pm 1.00$ & $24.7 \pm 1.53$ \\
JPS4 & $29.0 \pm 1.73$ & $22.3 \pm 1.53$ \\
JMS4 & $29.7 \pm 1.53$ & $23.7 \pm 0.58$ \\
\hline
\end{tabular}

*Including size of well $(8 \mathrm{~mm})$. Values are mean $\pm \mathrm{SD}(\mathrm{n}=3)$. B. subtilis: Bacillus subtilis, E. coli: Escherichia coli

Table 3: Antihelmintic activity of jaggery prepared using plant mucilage clarificants

\begin{tabular}{lll}
\hline Sample & Paralytic time (min) & Death time (min) \\
\hline Positive control & $21.6 \pm 0.548$ & $28.4 \pm 0.548$ \\
Negative control & - & - \\
JNC & $36.6 \pm 1.140$ & $47.6 \pm 0.548$ \\
JAV1 & $32.6 \pm 1.140$ & $42.6 \pm 1.140$ \\
JFS1 & $34.6 \pm 1.140$ & $44.6 \pm 1.140$ \\
JFG1 & $33.6 \pm 1.140$ & $42.6 \pm 1.140$ \\
JPS1 & $35.6 \pm 1.140$ & $45.6 \pm 1.342$ \\
JMS1 & $35.4 \pm 1.517$ & $46.6 \pm 1.342$ \\
JAV2 & $30.8 \pm 1.304$ & $40.6 \pm 1.140$ \\
JFS2 & $32.2 \pm 0.837$ & $43.6 \pm 1.140$ \\
JFG2 & $31.8 \pm 1.304$ & $42.6 \pm 1.140$ \\
JPS2 & $33.6 \pm 1.140$ & $44 \pm 0.707$ \\
JMS2 & $33.6 \pm 1.140$ & $44.6 \pm 1.140$ \\
JAV4 & $28.6 \pm 1.140$ & $39.6 \pm 1.140$ \\
JFS4 & $31.6 \pm 1.140$ & $41.6 \pm 1.140$ \\
JFG4 & $30.6 \pm 1.140$ & $40.6 \pm 1.140$ \\
JPS4 & $32.4 \pm 1.140$ & $42.6 \pm 1.140$ \\
JMS4 & $32.4 \pm 1.140$ & $43.6 \pm 1.140$ \\
\hline
\end{tabular}

Values are mean $\pm \operatorname{SD}(n=6)$

Acidic $\mathrm{pH}$ level of natural sweeteners may prevent the growth of many helminths and natural sweeteners have a saturated mixture of saccharides. This mixture has a low water activity and hence water unavailable for worms and creates poor environment for their growth. In addition, total phenol content was higher in $0.4 \%$ plant mucilage clarificants of $A$. vera (JAV4) derived jaggery and polyphenolic compounds are known to have antihelmintic activity [53]. Phenolic compounds may interfere with energy generation in helmintic parasites by uncoupling oxidative phosphorylation [54]. The important effect of tannins on helmintic life is that they bind with free proteins in the gastrointestinal tract of the host animal and also with glycoprotein on the cuticle of parasite and results in the death of parasite [55]. Flavonoids and terpenoids of plant extract were also reported to have antihelmintic properties [56,57]. The polyphenols content and flavonoids of sugarcane alone in jaggery may have contributed to the observed antihelmintic effect against earthworm.

\section{CONCLUSIONS}

Jaggery samples prepared using plant mucilage clarificants from A. vera, flax seed, fenugreek, purslane and Malabar spinach sources including control (without clarificants) were evaluated for total phenolic content, total flavonoid content and reducing power. In addition, the antibacterial activity and antihelmintic activity were also carried out.
Results indicated a dose-dependent increased total phenol content and reducing power in test jaggery compared to control. A. vera-treated jaggery was very effective in inhibiting Gram-positive and Gram-negative bacteria followed by fenugreek treated jaggery. Further, $A$. vera-treated jaggery had better paralytic as well as death time against roundworms in vitro compared to control and jaggery prepared without clarificants. Overall, the jaggery prepared using plant mucilage as clarificants had higher total phenols and flavonoids and exhibited enhanced reducing power, antibacterial activity and antihelmintic activity. Thus, the application of plant mucilage during sugarcane juice clarification may be recommended as an alternative to synthetic chemical clarificants for the production of nutraceutical jaggery.

\section{ACKNOWLEDGMENTS}

The authors are thankful to the University of Mysore, for providing opportunity and facilities to carry out this research work.

\section{AUTHOR'S CONTRIBUTION}

The present research idea was conceived and supervised by Harishnayaka. M.A. The jaggery samples were prepared using plant mucilage clarificants by Lava Chikkappaiah supported by Venkatesh. K.S. The bioactivity experiments and statistical analysis were carried out by Lava Chikkappaiah, Gunashree. B.S, and Sudharshan. S. Manuscript preparation was carried out by Lava Chikkappaiah under the supervision of Harishnayaka. M.A.

\section{CONFLICTS OF INTEREST}

We declare that there are no conflicts of interest.

\section{REFERENCES}

1. Roy SC. Monograph of the Gur Industry in India. Kanpur: India Institute of Sugar Technop; 1951. p. 55-64, 74-9.

2. Rao PV, Madhusweta D, Das SK. Jaggery a traditional Indians sweetener. Indian J Tradit Know 2007;6:95-102.

3. Jaffe RW. Health effects of non-centrifugal sugar (NCS): A review. Sugar Tech 2012;14:87-94.

4. Sahu AP, Saxena AK. Enhanced translocation of particles from lungs by jaggery. Environ Health Perspect 1994;102 Suppl 5:211-4.

5. Singh N, Kumar D, Raisuddin S, Sahu AP. Genotoxic effects of arsenic: Prevention by functional food-jaggery. Cancer Lett 2008;268:325-30.

6. Okabe, Toda TT, Inafuku M, Wada K, Iwasaki H, Oku H. Antiatherosclerotic functions of Kokuto, Okinawan non centrifuged cane sugar. J Agr Food Chem 2009;57:69-75.

7. Nayaka H, Sathisha UV, Manohar MP, Chandrashekar KB, Dharmesh SM. Cytoprotective and antioxidant activity studies of jaggery sugar. Food Chem 2009;115:113-8.

8. El-Abasy M, Motobu M, Shimura K, Na KJ, Kang CB, Koge K, et al. 
Immunostimulating and growth-promoting effects of sugar cane extract (SCE) in chickens. J Vet Med Sci 2002;64:1061-3.

9. Molina V, Noa M, Arruzazabala L, Carbajal D, Más R. Effect of D-003, a mixture of very-long-chain aliphatic acids purified from sugarcane wax, on cerebral ischemia in Mongolian gerbils. J Med Food $2005 ; 8: 482-7$

10. Ledón N, Casacó A, Rodríguez V, Cruz J, González R, Tolón Z, et al. Anti-inflammatory and analgesic effects of a mixture of fatty acids isolated and purified from sugar cane wax oil. Planta Med 2003;69:367-9.

11. Maurício Duarte-Almeida J, Novoa AV, Linares AF, Lajolo FM, Inés Genovese M. Antioxidant activity of phenolics compounds from sugar cane (Saccharum officinarum L.) juice. Plant Foods Hum Nutr 2006;61:187-92.

12. Prasad P, Kumar PP, Satyavathi K, Prabhakar MC. Comparatives studies on anthelmintic activity of natural sweeteners. Res J Pharma Bio Chem Sci 2010;1:510-14.

13. Vinutha C, Sudarshan S, Pradeep S, Nayaka MA. Antioxidant activity of sugarcane jaggery with neem (Azadirachta indica) leaf extract. Int $\mathbf{J}$ Recent Sci Res 2014;1:99-101.

14. Nayaka MA, Vinuta C, Sudarshan S, Manohar MP. Physico-chemical, antioxidant and sensory attributes of ginger (Zingiber officinale) enriched jaggery of different sugarcane varieties. Sugar Tech 2015;17:305-13

15. Repetto MG, Llesuy SF. Antioxidant properties of natural compounds used in popular medicine for gastric ulcers. Braz J Med Biol Res 2002;35:523-34

16. Sachidanandam K, Fagan SC, Ergul A. Oxidative stress and cardiovascular disease: Antioxidants and unresolved issues. Cardiovase Drug Rev 2005;23:115-32.

17. Halliwell B. Oxidative stress and cancer: Have we moved forward? Biochem J 2007;401:1-1

18. Shah SV, Baliga R, Rajapurkar M, Fonseca VA. Oxidants in chronic kidney disease. J Am Soc Nephrol 2007;18:16-28.

19. Scalbert A, Johnson IT, Saltmarsh M. Polyphenols: Antioxidants and beyond. Am J Clin Nutr 2005;81:215S-217S.

20. Shankunthala VA. Proceeding of National Seminar on Jaggery Manufacture and Storage; 1985. P. 90-3.

21. Baboo B. Nutritive sweeteners from sugar crops: Development of jiggery. J Agr Eng 1991;1:252-63.

22. Mungare TS, Jadhav HD, Patil JP, Hasure IL, Jadhav BS, Jaswant S. Clarification technique for production of quality jaggery. Co op. Sugar 2000;32:283-5.

23. Ragavan T, Thirumurugan A, Sathiya K, Vadana SS. A case study: Studies on quality jaggery (gur) production with organic clarificants. Int J For Crop Improv 2011;2:207-10.

24. Kharwade RS, More SM, Mahajan UN. Formulation and evaluation of gastroretentive floating tablet using Hibiscus rosa-Sinensis mucilage. Asian J Pharm Clin Res 2017;10:444-8

25. Chikkappaiah L, Nayaka HM, Manohar MP, Santhosh C, Properties of liquid jaggery prepared using plant mucilage as clarificant. Int J Recent Sci Res 2017;8:19590-5.

26. Shafi N, Khan L, Khan GA. Commercial extraction of gel from Aloe vera $(\mathrm{L})$ leaves. J Chem Soc Pak 2000;22:47-9.

27. Inamdar M, Abhang P, Momin M. Isolation and evaluation of fenugreek, flaxseed mucilages and its use as a pharmaceutical binder. Int J Pharm Technol 2012;4:4766-77.

28. Chattoraj S, Bandyopadhyay AK. Development and evaluation of donut matrix tablets of bracofen using mucilaginous polymer from Portulaca oleracea Linn. Pharm Ind 2010;72:11.

29. Hameed AM, Hamied RS, Shnain ZY. Drag-reducing agent for aqueous liquid flowing in turbulent mode through pipelines. Al-Khwarizmi Eng J 2014; 10:15-22

30. Kulkarni GT, Gowthamarajan K, Brahmajirao G, Suresh B. Evaluation of binding properties of selected natural mucilages. J Sci Ind Res 2002;61:529-32

31. Chang CM, Yang H, Chern JW. Estimation of total flavonoid content in propolis by two complementary colorimetric methods. J Food Drug Anal 2002:10:178-82.

32. Chikkappaiah L, Nayaka MA, Mahadevaiah H, Kumar GM. Preparation of plant mucilage clarificants and their effect on jaggery processing of sugarcane variety Co 86032. Int J Pharm Pharm Sci 2017;9:32-6.

33. McDonald S, Prenzler PD, Autolovich M, Robards K. Phenolic content and antioxidant activity of olive extracts. Food Chem 2001;73:73-84.

34. Yen GC, Chen HY. Antioxidant activity of various tea extracts in relation to their ant mutagenicity. J Agr Food Chem 1995;43:27-32.

35. National Committee for Clinical Laboratory Standards. Performance standards for Antimicrobial Susceptibility Testing, $9^{\text {th }}$ Informational Supplement. Approved standard M100-S9. Wayne, Pa: National Committee for Clinical Laboratory Standards; 1999.

36. Aiyegoro OA, Okoh AI. Preliminary phytochemical screening and in vitro antioxidant activities of the aqueous extract of Helichrysum longifolium DC. BMC Complement Altern Med 2010;10:21.

37. Meir S, Kanner J, Akiri B, Hadas SP. Determination and involvement of aqueous reducing compounds in oxidative defense systems of various senescing leaves. J Agr Food Chem 1995;43:1813-7.

38. Harborne JB, Williams CA. Advances in flavonoid research since 1992. Phytochemistry 2000;55:481-504.

39. Payet B, Shum Cheong Sing A, Smadja J. Assessment of antioxidant activity of cane brown sugars by ABTS and DPPH radical scavenging assays: Determination of their polyphenolic and volatile constituents. J Agric Food Chem 2005;53:10074-9.

40. Takara K, Matsui D, Wada K, Ichiba T, Nakasone Y. New antioxidative phenolic glycosides isolated from Kokuto non-centrifuged cane sugar. Biosci Biotechnol Biochem 2002;66:29-35.

41. Dittrich R, El-Massry F, Kunz K, Rinaldi F, Peich CC, Beckmann MW, et al. Maillard reaction products inhibit oxidation of human low-density lipoproteins in vitro. J Agr Food Chem 2003;51:3900-4.

42. Paton NH, Duong M. Sugar-cane phenolics and $1^{\text {st }}$ expressed juice color role of chlorogenic acid and flavonoids in enzymatic browning of cane juice. Int Sugar Journal 1992;94:170-6.

43. McGhie TK. Analysis of sugarcane flavonoids by capillary zone electrophoresis. J Chromatrography 1993;634:107-12.

44. Rice-Evans CA, Miller NJ, Paganga G. Structure-antioxidant activity relationships of flavonoids and phenolic acids. Free Radic Biol Med 1996;20:933-56.

45. Noa M, Mendoza S, Más R, Mendoza N. Effect of D-003, a mixture of high molecular weight primary acids from sugar cane wax, on CL4Cinduced liver acute injury in rats. Drugs Exp Clin Res 2002;28:177-83.

46. EFSA. Scientific opinion on the substantiation of health claims related to various food(s)/food constituents and protection of cells from premature aging, antioxidant activity, antioxidant content and antioxidative properties, and protection of DNA, proteins, and lipids from oxidative damage pursuant to Article 13(1) of Regulation (EC) No. 1924/2006. EFSA J 2010;8:1489.

47. Yoko N, Takara K, Wada K, Tanaka J, Yogi S, Nakatani NN Antioxidative compounds isolated from Kokuto, non-centrifugal cane sugar. Biosci Biotechnol Biochem 1996;60:1714-6.

48. Sies H. Antioxidant in Disease, Mechanism and Therapy. New York: Academic Press; 1996.

49. Shan B, Cai YZ, Sun M, Corke H. Antioxidant capacity of 26 spice extracts and characterization of their phenolic constituents. J Agric Food Chem 2005;53:7749-59.

50. Gibbs HC. Epidemiology, Diagnosis and Control of Gastrointestinal parasitism. Kenya: ILARD; 1986. p. 121.

51. Gasbarre CL, Stout LW, Leighton AE. Gastrointestinal nematodes of cattle in the North Eastern US: Results of a producer survey. Vet Parasitol 2001;101:29-44.

52. Saeed M, Iqbal Z, Jabbar A. Oxfendazole resistance in gastro-intestinal nematode of beetal goats at livestock farms of Punjab (Pakistan). Acta Veterinaria Brno 2007;76:79-85.

53. Bate-smith EC. The phenolic constituents of plants and their taxonomic significance I Dicotyledons. J Linn Soc (Bot) 1962;58:95-173.

54. Martin RJ. Mode of action of antihelmintic drugs. Vet J 1997;154:11-34.

55. Thomson DP, Geary TG. The structure and function of helminth surface. In: Marr JJ, editor. Biochemistry and Molecular Biology of Parasite. $1^{\text {st }}$ ed. New York: Academic Press; 1995. p. 203-32.

56. Pessoa LM, Morais SM, Bevilaqua CM, Luciano JH. Anthelmintic activity of essential oil of Ocimum gratissimum Linn. And eugenol against Haemonchus contortus. Vet Parasitol 2002;109:59-63.

57. Lahlou M. Potential of Origanum compactum as a cercaricide in morocco. Ann Trop Med Parasitol 2002;96:587-93. 